\title{
Applying pyrolysis-gas chromatography/mass spectrometry to the identification of oriental lacquers: study of two lacquered shields
}

\author{
José Carlos Frade • Maria Isabel Ribeiro • José Graça • \\ José Rodrigues
}

Received: 15 June 2009 /Revised: 31 July 2009 /Accepted: 4 August 2009 /Published online: 25 August 2009

(C) Springer-Verlag 2009

\begin{abstract}
Oriental lacquers have been used as coating materials for thousands of years for wooden, ceramics, leather and metal objects. Lacquers are natural polymers obtained from three species growing in different regions of Asia: Rhus vernicifera (China, Japan and Korea); Rhus succedanea (Vietnam and Taiwan); and Melanorrhoea usitate (Myanmar and Thailand). The identification of lacquer films is important for conservation and restoration purposes, as well as for art history studies because it may help in determining the origin of the lacquered objects. In this work, pyrolysis-gas chromatography/mass spectrometry using a filament-type pyrolyser was successfully applied to the characterization of oriental lacquers. A method to identify the three kinds of lacquer was developed and applied to the study of two lacquered shields imported from Asia in the sixteenth century. The materials that constitute the shields were also examined by Fourier-transform
\end{abstract}

\footnotetext{
J. C. Frade $\cdot$ M. I. Ribeiro

Instituto dos Museus e da Conservação,

Laboratório José de Figueiredo,

Rua das Janelas Verdes 37,

1249-018 Lisboa, Portugal

J. C. Frade $\cdot$ J. Rodrigues

Tropical Research Institute of Portugal,

Forestry and Forest Products Group,

Tapada da Ajuda,

1349-017 Lisboa, Portugal

J. C. Frade $(\bowtie) \cdot J$. Graça

Centro de Estudos Florestais,

Departamento de Engenharia Florestal,

Instituto Superior de Agronomia,

Tapada da Ajuda,

1349-017 Lisboa, Portugal

e-mail: fradejcp@gmail.pt
}

infrared microspectroscopy and details of the lacquering technique are reported.

Keywords Oriental lacquer $\cdot$ Rhus vernicifera $\cdot$ Rhus succedanea $\cdot$ Melanorrhoea usitate $\cdot$ Py-GC/MS · FTIR- $\mu \mathrm{s}$

\section{Introduction}

Oriental lacquers have been used as coating materials for thousands of years for wooden, ceramics, leather and metal objects [1-3]. Applying oriental lacquer on a object, requires great patience, artistic talent and creativity $[3,4]$. The best quality objects are produced through a long manufacturing process in which a large number of lacquer layers, alone or mixed with other materials, are applied [3-5]. The contact between Portuguese and Oriental cultures, during the sixteenth century and in the beginning of the seventeenth century, originated a series of new typologies of religious and civil artworks [6, 7]. Local materials, techniques and decoration styles were adapted to the Western models taken to the East. A great number of works of art exhibiting hybrid decorations with Indian, Chinese, Muslim, Burmese, Thai, Japanese, and European influences are present in many European, namely Portuguese museums, and in private collections [6, 7]. Among those objects, there is a set of lacquered objects, classified as a special group within the Indo-Portuguese furniture, whose origin is still unknown [7]. The identification of the type of lacquer applied in the manufacture of those artworks would certainly contribute to a better classification, and allow the determination of their provenance or at least circumscribe the area of production.

Lacquers are natural polymers obtained from three species of trees growing in different regions of Asia [1, 2]: Rhus 
vernicifera in China, Japan and Korea; Rhus succedanea in Vietnam and Taiwan (Formosa); Melanorrhoea usitate in Myanmar (Burma) and Thailand. Liquid lacquer is the sap of these trees and is composed of a mixture of catechol derivatives, water, polysaccharides, glycoproteins and enzymes. The catechol derivatives mixture has different composition for each kind of lacquer, and it has the name of urushiol for $R$. vernicifera, laccol for $R$. succedanea and thitsiol for M. usitate $[1,2,8]$.

Lacquers polymerize through an enzyme-catalysed oxidation mechanism leading to the formation of films with a high level of cross-linking, which are insoluble by most solvents and difficult to analyse [2]. Being able to distinguish the three types of lacquer is very important for conservation and restoration purposes, as well as for art history studies. The identification of the lacquer from a given lacquered work of art may help in determining its geographical origin, since lacquer species develop in welldefined regions in Asia.

Due to the insolubility and complex structure of the lacquer films, only solid-state methods have been applied to their characterization, and the only method capable of distinguishing these materials is pyrolysis-gas chromatography/mass spectrometry (Py-GC/MS) [2, 8].

The potential to analyse non-volatile and insoluble complex materials, and the small quantity of sample required makes it very attractive in the cultural heritage field and has been widely applied to the characterization of many organic materials found in artworks [9, 10]. Py-GC/ MS with a furnace-type pyrolyser was already applied to the characterization of oriental lacquers by Niimura et al., and some advances were made on the polymer structure, pyrolysis mechanisms and lacquer type distinction $[2,11,12]$. The filament-type pyrolyser was also employed in the analysis of polychrome Chinese archaeological objects and in the characterization of some of the most common organic materials used in ancient Chinese artworks, such as Chinese lacquer, tung oil, colophony and peach gum. In these studies, pyrolysis was carried out in the presence of tetramethylammonium hydroxide (TMAH) as the methylating agent, and some fragment ions were established as fingerprint ions to distinguish those materials. In the case of Chinese lacquer, the fingerprint ion used was the methylated dihydroxytropylium ion $m / z=151[13,14]$.

In the present work, different results were obtained from those reported $[2,11]$; due to the use of a filament-type pyrolyser, a new method to identify the three kinds of lacquer was developed and applied to the study of two lacquered shields imported from Asia of unknown origin. One belongs to the collection of the MNSR-"Museu Nacional Soares dos Reis" (Soares dos Reis National Museum) and the other is from a private collection. The materials that constitute the shields were also examined by
Fourier-transform infrared microspectroscopy (FTIR- $\mu$ s) and the lacquering technique was assessed.

\section{Experimental}

\section{Reference lacquer samples}

Liquid lacquer samples from $R$. vernicifera (produced in Johouji, Iwate Prefecture, Japan), R. succedanea (Vietnam) and M. usitate (Myanmar) species were kindly offered by Professor Miyakoshi from Meiji University, Japan. Films of lacquer from the three species were prepared in glass slides and then placed for 7 days in a chamber at $25^{\circ} \mathrm{C}$ and $80 \%$ of relative humidity. After this period, films were stored in the dark for 8 months.

\section{Shields samples}

Samples from the two shields were collected using a surgical scalpel. Cross-sections of the samples were prepared and examined under white light using a Leitz WETZLAR optical microscope, with a $\times 10$ ocular and a $\times 11$ objective, coupled to a Leica DC500 digital camera.

\section{Py-GC/MS}

Py-GC/MS experiments were carried out with a CDS Pyroprobe 2000 coil filament pyrolyser, attached to an Agilent 6890 $\mathrm{N}$ gas chromatographer (GC) equipped with a $5975 \mathrm{~N}$ mass spectrometer (MS). The pyrolyser is connected to the $\mathrm{GC}$ by a heated interface set at $250^{\circ} \mathrm{C}$, and samples (about $100-50 \mu \mathrm{g}$ ) were pyrolysed at $950{ }^{\circ} \mathrm{C}$ for $10 \mathrm{~s}$. A HP- $5 \mathrm{~ms}$ fused silica capillary column (5\% diphenyl-95\% dimethylpolysiloxane, $30 \mathrm{~m} \times 0.25 \mathrm{~mm}$ i.d., $0.25 \mu \mathrm{m}$ film thickness) was used for the gas chromatographic separation. Helium gas flow in the column was set at $1.5 \mathrm{~mL} / \mathrm{min}$, and the $\mathrm{GC}$ temperature programme was as follows: initial temperature $50{ }^{\circ} \mathrm{C}$, hold for $10 \mathrm{~min}$, increase at $6{ }^{\circ} \mathrm{C} / \mathrm{min}$ up to $290{ }^{\circ} \mathrm{C}$, hold for $2 \mathrm{~min}$. Mass spectrometer operated under EI conditions $(70 \mathrm{eV}$ ) in the range from 45 to $500 \mathrm{~m} / z$. Pyrolysis products were identified by interpretation of mass spectra and by comparison with NIST and Wiley libraries.

\section{FTIR- $\mu \mathrm{s}$}

Samples were analysed in a Thermo Nicolet Nexus 670 FTIR spectrometer coupled to a Continu $\mu \mathrm{m}$ IR microscope. FTIR spectra were collected in transmission mode using the compression diamond Spectra-Tech $\mu$ Sample Plan cell. Each FTIR spectrum is the average of 254 scans collected at $4 \mathrm{~cm}^{-1}$ resolution, in the region from $4,000 \mathrm{~cm}^{-1}$ to $650 \mathrm{~cm}^{-1}$. 


\section{Results}

Lacquer Py-GC/MS analysis

Pyrograms of the three types of lacquer are presented in Fig. 1. More than 130 pyrolysis products were identified in each lacquer and the main products are alkanes, alkenes, alkyl and alkenyl benzenes, alkyl and alkenyl phenols and derivatives of indene and naphthalene. The main difference between the three lacquers is in the relative quantity of the pyrolysis products. The pyrograms of $R$. vernicifera and $R$. succedanea lacquers are similar, but $R$. succedanea pyrogram reveals a greater quantity of hexadecane, heptadecane, and hexadecene and heptadecene isomers. M. usitate pyrogram is different and shows greater amounts of alkyl and alkenyl benzenes, with undecenylbenzene being the most abundant.

Extracting the ions $m / z=104$ and $m / z=108$ from the pyrograms, characteristic profiles are obtained for each lacquer, and as a result, their distinction is easier. Figure 2 shows the $m / z=$ 104 and $m / z=108$ mass chromatograms of the three lacquers and the main compounds identified are presented in Table 1.

$m / z=104$ mass chromatograms show a sequence of peaks corresponding to a series of alkenyl benzenes. $\mathrm{m} / \mathrm{z}=$
104 ion $\left[\mathrm{C}_{6} \mathrm{H}_{5} \mathrm{CH}=\mathrm{CH}_{2}\right]^{+}$is a prominent peak in alkenyl benzenes mass spectra, arising essentially from the rearrangement of two other fragment ions $(m / z=174$ and 145) [15]. The profile presented by this alkenyl benzenes series is different for each kind of lacquer and this allows distinguishing between the three types. In the lacquer from $R$. vernicifera species, the most significant peaks in the mass chromatogram correspond to pentenyl benzene and hexenyl benzene. Next to these peaks, at the retention times $18.91 \mathrm{~min}$ and $22.23 \mathrm{~min}$, two other relevant peaks are visible, which were identified as 1,2,3,4-tetrahydronaphthalene and 2,3-dihydro- $1 \mathrm{H}$-indenone, respectively. The mass spectra of these compounds also exhibit the $m / z=104$ ion. For $R$. succedanea lacquer, octenyl benzene peak has the highest relative intensity, and in the case of $M$. usitate undecenyl benzene is the most intense peak in the chromatogram.

In relation to the $m / z=108$ ion, it corresponds to the hydroxytropylium ion in alkyl phenols mass spectra, and a series of alkyl phenols is obtained when the ion is extracted from the lacquers pyrograms. In this case, it is only possible to discriminate $R$. succedanea lacquer from $R$. vernicifera and $M$. usitate lacquers. $R$. vernicifera and $M$. usitate

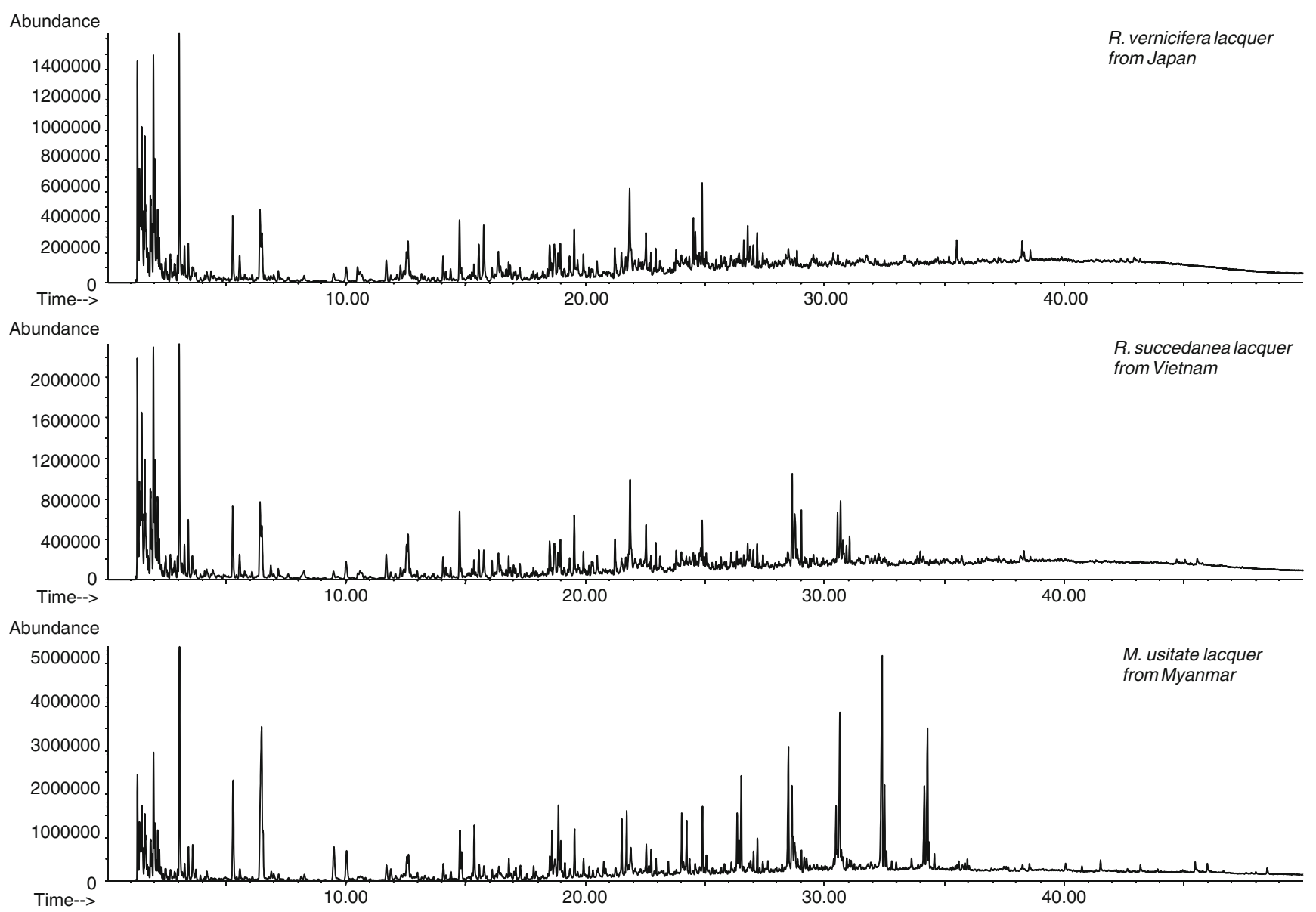

Fig. 1 Typical pyrograms of the three types of oriental lacquer 

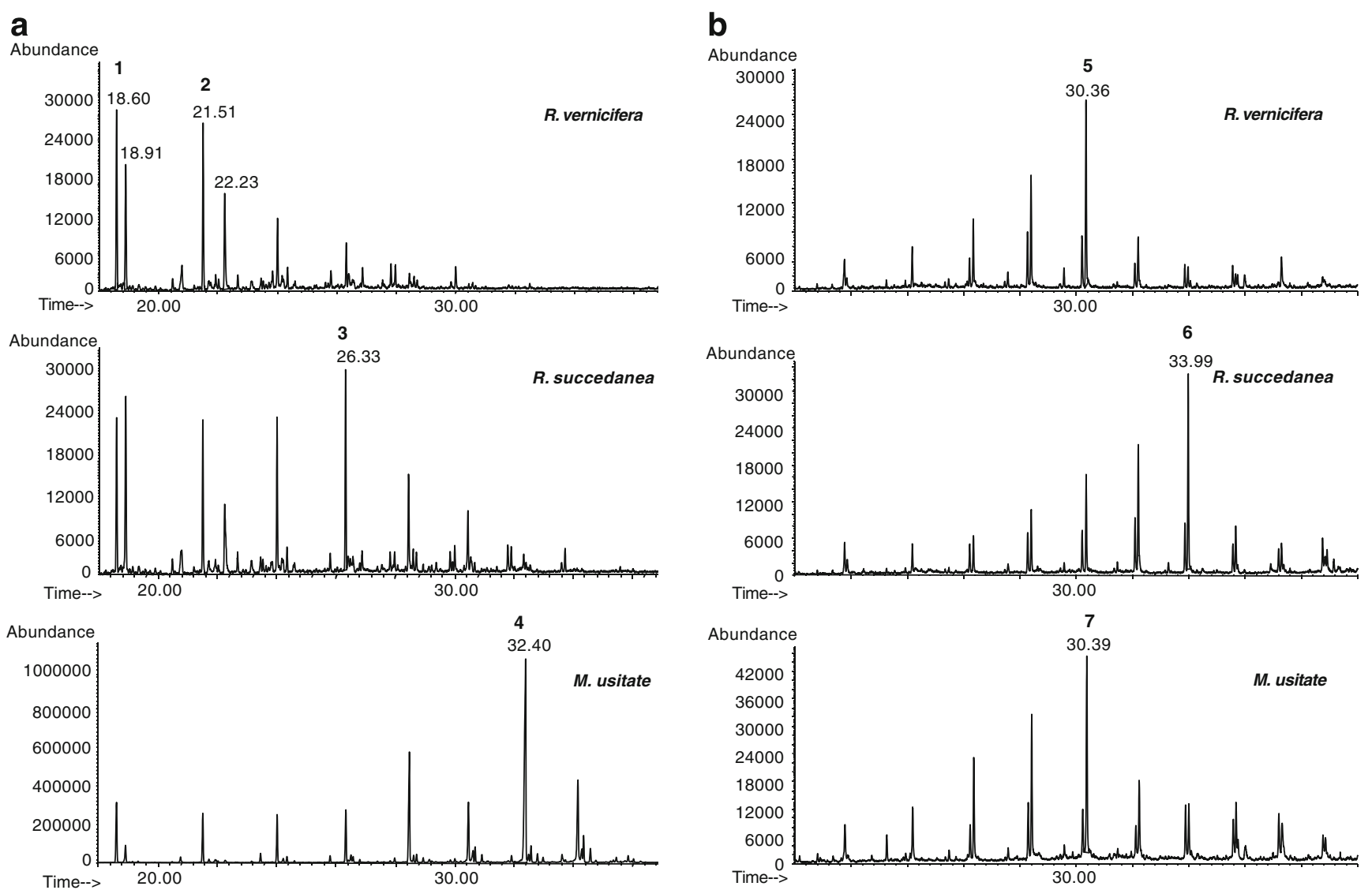

Fig. $2 \mathrm{~m} / \mathrm{z}=104$ mass chromatogram (a) and $\mathrm{m} / \mathrm{z}=108$ mass chromatogram (b) of the three types of oriental lacquer

Table 1 Some of the most relevant alkenyl benzenes and alkyl phenols identified respectively in the $\mathrm{m} / \mathrm{z}=104$ and $\mathrm{m} / \mathrm{z}=108$ mass chromatograms

\begin{tabular}{lcll}
\hline Label & Retention time $(\mathrm{min})$ & Compound & MW \\
\hline Alkenyl benzenes profile $(\mathrm{m} / \mathrm{z}=104)$ & & \\
1 & 18.60 & Pentenyl benzene & 146 \\
2 & 21.51 & Hexenyl benzene & 160 \\
& 24.04 & Heptenyl benzene & 174 \\
3 & 26.33 & Octenyl benzene & 188 \\
& 28.49 & Nonenyl benzene & 202 \\
& 30.48 & Decenyl benzene & 216 \\
4 & 32.40 & Undecenylbenzene & 230 \\
& 34.16 & Dodecenyl benzene & 244 \\
Alkyl phenols profile $(m / z=108)$ & & \\
& 26.35 & Pentyl phenol & 164 \\
& 28.41 & Hexyl phenol & 178 \\
5,7 & 30.36 & Heptyl phenol & 192 \\
& 32.22 & Octyl phenol & 206 \\
6 & 33.99 & Nonyl phenol & 220 \\
& 35.68 & Decyl phenol & 234 \\
\hline
\end{tabular}

lacquers have identical alkyl phenols profiles, with heptyl phenol being the highest intensity peak in the $m / z=108$ mass chromatograms. For $R$. succedanea lacquer, nonyl phenol is the most intense peak.

Study of the two lacquered shields

One sample was collected from each shield in areas with gold decorations, and sampling sites and samples crosssections are presented in Fig. 3. FTIR spectra of the lacquer and ground layers of the two shields are displayed in Figs. 4 and 5.

The lacquering technique employed during the execution of the shields is different, as shown by the cross-section microphotographs and by the FTIR spectra acquired. Crosssections reveal that ground layers in the two shields have a different nature. In the shield from MNSR, a mixture of clay and a protein-based material was identified by FTIR- $\mu$ s in the ground layer, whereas in the shield from the private collection, lacquer was applied directly on the support.

The absorption bands in the MNSR's shield ground layer spectrum at $3626 \mathrm{~cm}^{-1}(\mathrm{O}-\mathrm{H}$ stretching $), 1,046 \mathrm{~cm}^{-1}$ (O-Si-O stretching), $797 \mathrm{~cm}^{-1}(\mathrm{Si}-\mathrm{O}$ stretching), $778 \mathrm{~cm}^{-1}$ (Si-O stretching), and $695 \mathrm{~cm}^{-1}$ (Si-O deformation) 
Fig. 3 Shield from the MSRN (a), shield from the private collection (b), and respective photomicrographs

(c, d) - original magnification $\times 100$ - of the cross-sections of the collected samples. The red circles represent the sites from where the samples were taken
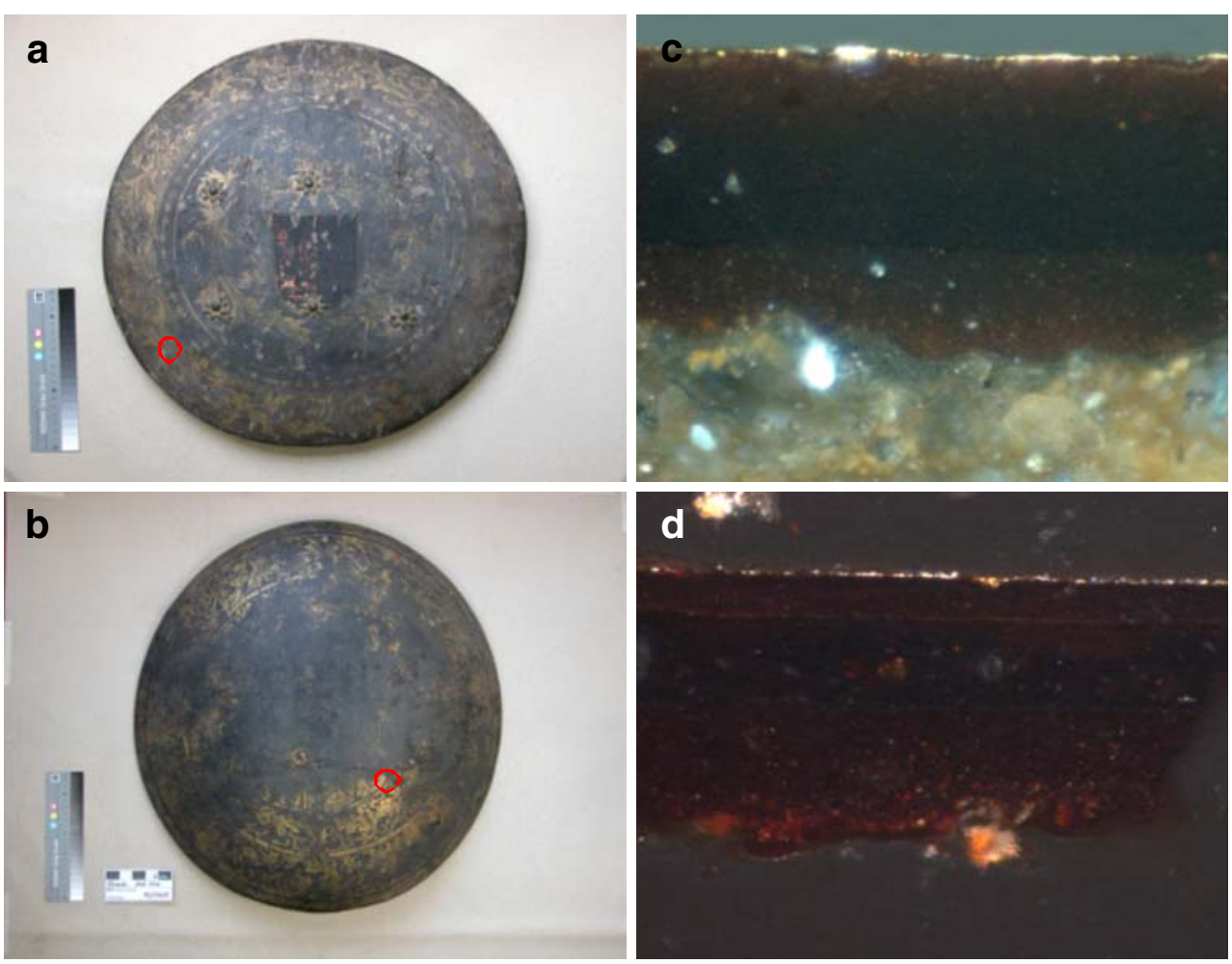

are due to the presence of silicates that indicate the presence of clay, and the bands at 2,929 $\mathrm{cm}^{-1}$ (C-H stretching), $1,650 \mathrm{~cm}^{-1}$ (amide I), 1,536 $\mathrm{cm}^{-1}$ (amide II) and $1,453 \mathrm{~cm}^{-1}$ (C-H deformation) are attributed to the presence of protein $[16,17]$.
In relation to the ground layer of the shield from the private collection and to the lacquer layers of the two shields, all bands appearing in the spectra are the characteristic absorptions of oriental lacquers [1, 17-19]: the broad band in the region $3,600-3,100 \mathrm{~cm}^{-1}$, and the

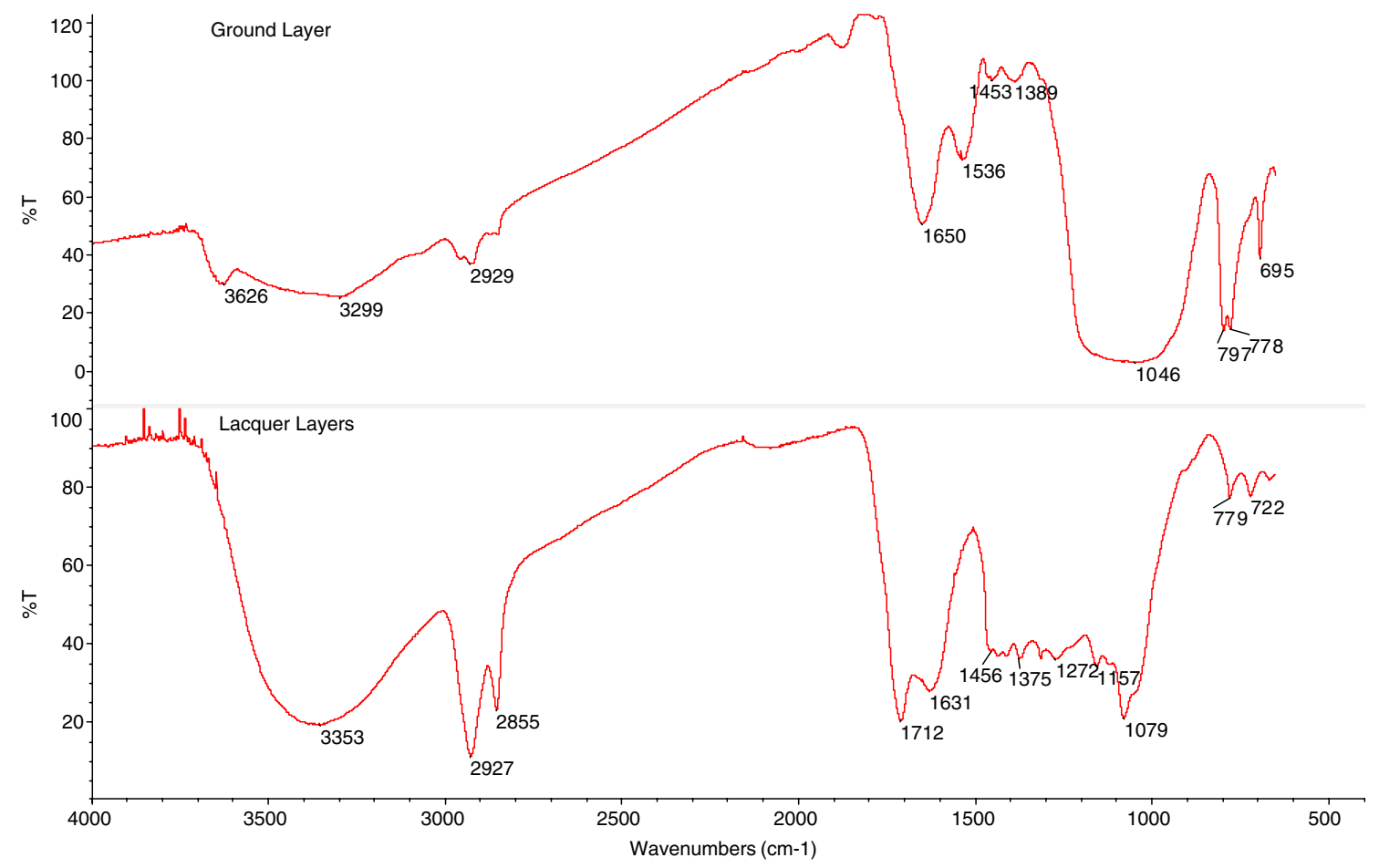

Fig. 4 FTIR spectra of the ground and lacquer layers from the sample collected in the shield from MNSR 


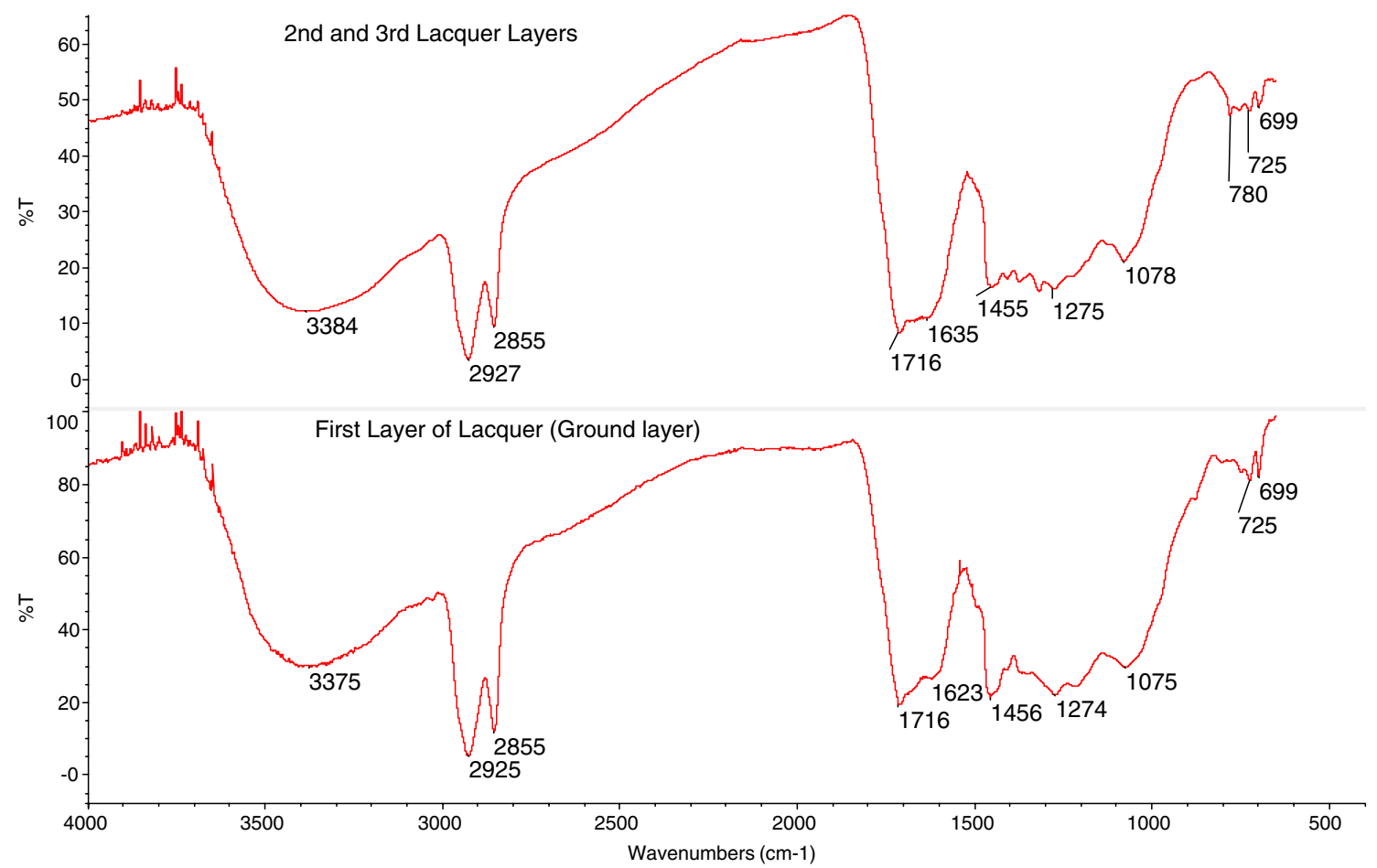

Fig. 5 FTIR spectra of the first layer of lacquer, considered as the ground layer, and of the lacquer layers above from the sample collected in the shield from the private collection

absorptions at about $2,925 \mathrm{~cm}^{-1}$ and $2,855 \mathrm{~cm}^{-1}$ are attributed, respectively, to $\mathrm{O}-\mathrm{H}$ and $\mathrm{C}-\mathrm{H}$ stretching vibrations; the peak at $1,450 \mathrm{~cm}^{-1}$ may be assigned to $\mathrm{C}-$ $\mathrm{H}$ deformation vibrations; at about $1710 \mathrm{~cm}^{-1}$ appears the carbonyl group vibration with a shoulder at c.a. $1,630 \mathrm{~cm}^{-1}$ that is due to the aromatic ring skeletal vibrations of the polymerized catechol derivatives; the absorptions in the region $1,300-1,000 \mathrm{~cm}^{-1}$ are assigned to $\mathrm{C}-\mathrm{O}$ stretching vibrations that have different contributions from different functional groups to their intensities, namely $\mathrm{C}-\mathrm{OH}$ groups, ether groups formed during the oxidative polymerization of lacquer and $\mathrm{C}-\mathrm{O}-\mathrm{C}$ glycosidic groups from the lacquer polysaccharides; the bands at about $1,275 \mathrm{~cm}^{-1}$ and $1,075 \mathrm{~cm}^{-1}$ are due to $\mathrm{C}-\mathrm{OH}$ stretching, respectively, in

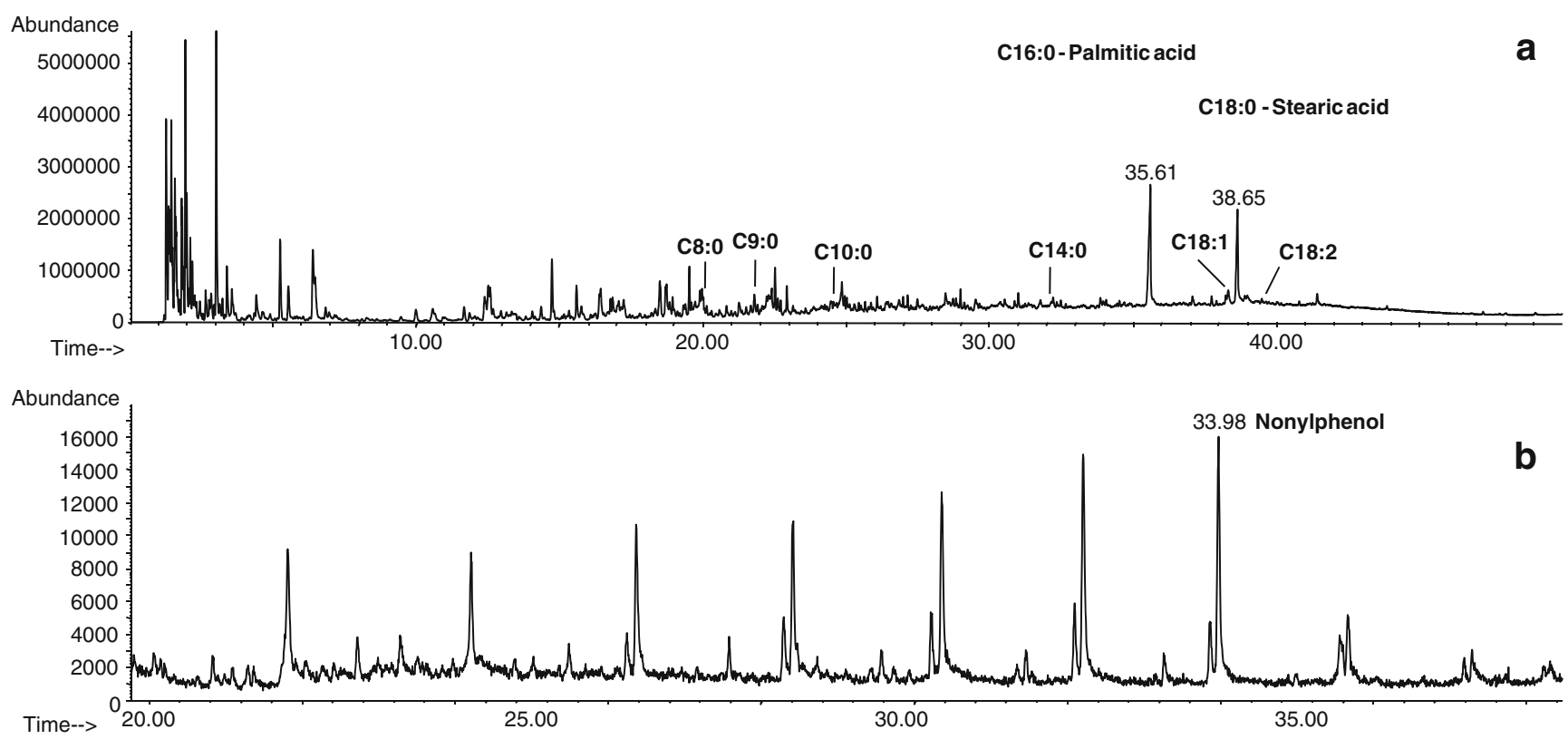

Fig. 6 Pyrogram (a) and $m / z=108$ mass chromatogram (b) of the lacquer from the MNSR shield 


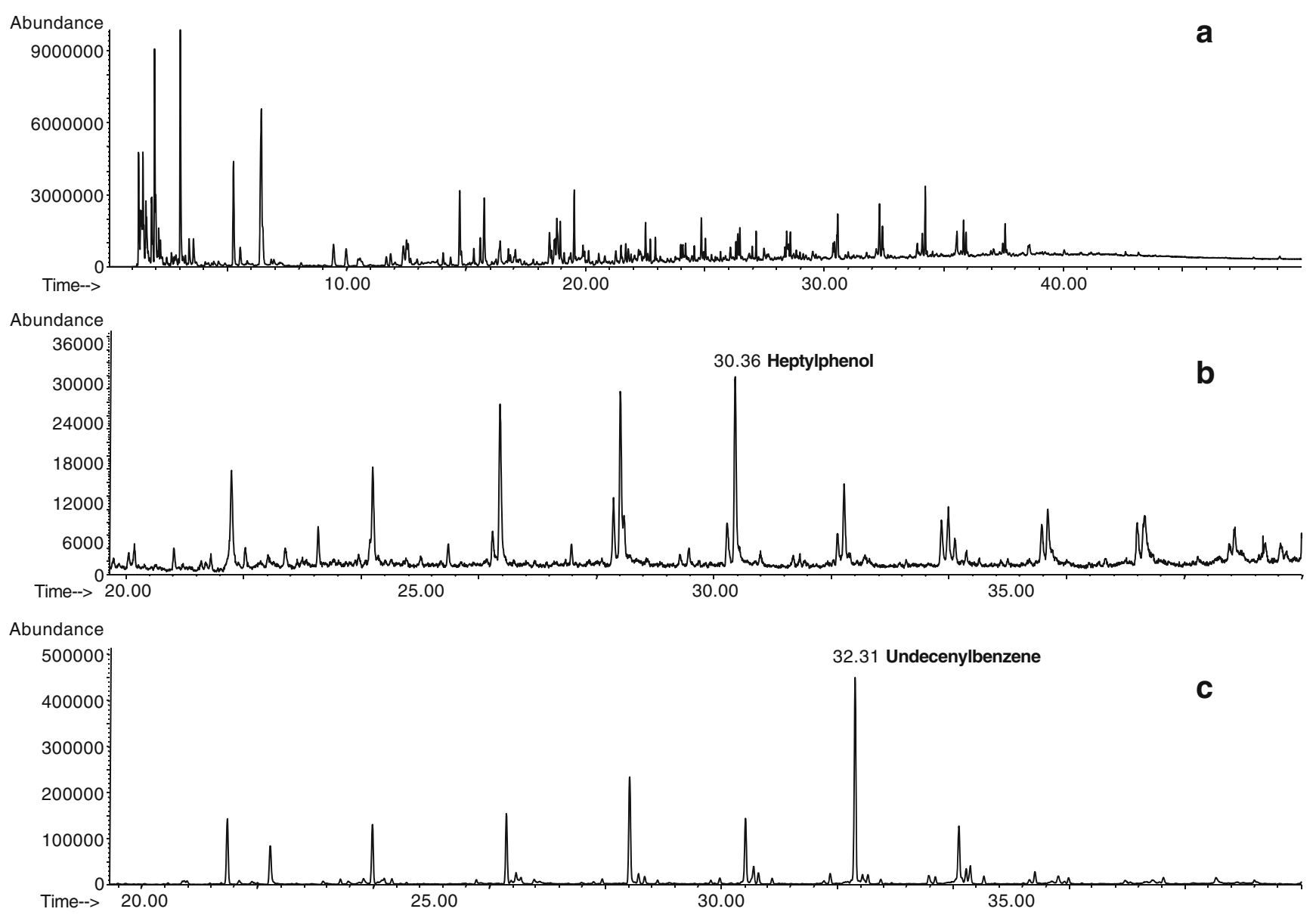

Fig. 7 Pyrogram (a), $m / z=108$ mass chromatogram (b) and $m / z=104$ mass chromatogram (c) of the lacquer from the shield of the private collection

phenolic groups and in lacquer polysaccharides; in the region $780-690 \mathrm{~cm}^{-1}$ some weak intensity absorption bands appear and are attributed to out-of-plane $\mathrm{C}-\mathrm{H}$ deformation vibrations.

In the spectrum of the ground layer of the MNSR's shield, one should consider the possibility of some of the protein bands and the intense broad band at $1,046 \mathrm{~cm}^{-1}$ to overlap the bands from the lacquer. None of the characteristic absorption bands of lacquer are visible in the spectrum, not even the intense carbonyl band. So, if indeed there is any lacquer in that layer, it must be in a very small quantity. On the other hand, if the traditional lacquering techniques are taken into account [3], it is most likely that the ground layer has only a proteinaceous material as binding medium.

\section{Py-GC/MS analysis of the lacquer}

The top layers of lacquer from the samples of the two shields were analysed by Py-GC/MS. Pyrograms and mass chromatograms obtained are presented in Figs. 6 and 7.
Table 2 Fatty acids identified in the pyrogram of the lacquer from the MNSR's shield

\begin{tabular}{llll}
\hline Label & Retention time (min) & Compound & MW \\
\hline C8:0 & 20.03 & Octanoic acid & 144 \\
C9:0 & 22.40 & Nonanoic acid & 158 \\
C10:0 & 24.51 & Decanoic acid & 172 \\
C14:0 & 32.15 & Tetradecanoic acid & 228 \\
C16:0 & 35.61 & Palmitic acid (hexadecanoic acid) & 256 \\
C18:1 & 38.32 & Oleic acid (octadecenoic acid) & 282 \\
C18:0 & 38.65 & Stearic acid (octadecanoic acid) & 284 \\
C18:2 & 39.49 & Linoleic acid (octadecadienoic acid) & 280 \\
\hline
\end{tabular}


In the case of the shield from MNSR, the pyrogram is different from that of reference films, and shows some peaks corresponding to fatty acids. The fatty acids identified are presented in Table 2, and the most abundant ones are palmitic (peak C16:0) and stearic (peak C16:0) acids. The remaining fatty acids occur only in trace quantities in the pyrogram. This means that a material such as oil was added to the lacquer. Mixing lacquer with oil is a common technique that does not require so much surface polishing to obtain the lustre usually associated to this kind of objects, as in the case of using lacquer alone [5]. In what concerns to the lacquer identification, the $m / z=108$ mass chromatogram (alkyl phenols) alone is enough to identify the lacquer as from $R$. succedanea species, since it is identical to the reference lacquer profile.

In relation to the shield from the private collection, the profile presented by the $m / z=108$ mass chromatogram indicates two hypotheses: $R$. vernicifera or $M$. usitate lacquer. Comparing the alkenyl benzenes profile $(\mathrm{m} / \mathrm{z}=$ 104) obtained with the reference profiles, the lacquer utilised in the manufacture of this artwork is unequivocally identified as lacquer from M. usitate.

The pyrogram obtained in the analysis of the lacquer from this shield also allows the lacquer identification, since it is clearly similar to the pyrogram of the $M$. usitate reference film. However, in the case of the MNSR's shield, the comparison between the pyrogram with the reference ones is not so obvious, being necessary to use the alkyl phenols profile to identify the lacquer.

\section{Conclusions}

Py-GC/MS is a powerful and versatile technique to identify oriental lacquers. Each type of lacquer has characteristic $m / z=104$ and $m / z=108$ mass chromatogram profiles that allow their discrimination. The application of the method developed to the study of the lacquered shields reveals that is possible to easily determine the origin of a lacquerware object. The lacquer from the shields was identified and results point out to different geographical origins, since the lacquers identified are from different species that grow in different regions in Asia. In addition, examining the crosssections of the samples collected from the shields, in combination with data provided by the FTIR- $\mu$ s and Py-GC/MS analyses allowed to characterise the shields' technique of execution.
Another conclusion that can be drawn from the study of the shields is that the examination of the pyrogram itself is not enough to identify the lacquer type because other materials, such as oils or even lacquer degradation products, may be present in the lacquer and as a result the pyrogram may be modified to a point that does not allow the lacquer identification. So, the extraction of the $m / z=104$ and $m / z=108$ mass chromatograms and the comparison of their profiles with reference ones is the most secure and easy way to unambiguously identify the lacquer type.

Acknowledgements The authors wish to acknowledge Fundação para a Ciência e Tecnologia for financial support (PhD grant SFRH/ BD/27573/2006) and Professor Miyakoshi from Meiji University for the lacquer references.

\section{References}

1. Kumanotani J (1995) Prog Org Coat 26:163-195

2. Niimura N, Miyakoshi T, Onodera J, Higuchi T (1996) J Anal Appl Pyrol 37:199-209

3. Webb M (2000) Lacquer: technology and conservation. Butterworth-Heinemann, Oxford

4. Shôno-Sládek M (1994) The splendor of Urushi: the lacquer art collection at the Museum of East Asian Art, Cologne. Inventory catalogue with reflexions on cultural history. Museum of East Asian Art, Cologne

5. Leiria L (2001) BPJS 3:9-26

6. Abreu P (2005) Namban urushi objects in Portugal. The great family of Portuguese-Oriental furniture. In: National Research Institute for Cultural Properties (eds) The Role of Urushi in International Exchange. The 27th International Symposium on the Conservation and Restoration of Cultural Property, 3rd-5th December 2003, Tokyo, Japan

7. Carvalho PM, In: Carvalho PM (ed) O mundo da Laca, 2000 anos de história. Fundação Calouste Gulbenkian, Lisboa

8. Lu R, Kamiya Y, Miyakoshi T (2006) Talanta 70:370-376

9. Chiavari G, Prati S (2003) Chromatographia 58:543-554

10. Shedrinsky A, Baer NS (2007) In: Wampler TP (ed) Applied pyrolysis handbook, 2nd edn. CRC, Boca Raton

11. Niimura N, Miyakoshi T, Onodera J, Higuchi T (1996) Rapid Commun Mass Spectrom 10:1719-1724

12. Niimura N, Miyakoshi T (2003) J Mass Spectrom Soc Jpn 51:439-457

13. Chiavari G, Mazzeo R (1999) Chromatographia 49:268-272

14. He L, Nie MQ, Chiavari G, Mazzeo R (2007) Microchem J 85:347-353

15. Gerrard AF, Djerassi C (1969) J Am Chem Soc 91:6808-6814

16. Derrick MR, Stulik D, Landry JM (1999) Infrared spectroscopy in conservation science. Getty Conservation Institute, Los Angeles

17. Bellamy LJ (1975) The infra-red spectra of complex molecules. Chapman and Hall, London

18. Lu R, Kamiya Y, Miyakoshi T (2007) J Anal Appl Pyrol 78:172179

19. Niimura N, Miyakoshi T (2006) Talanta 70:146-152 